\title{
Approximation of Fixed Points of Weak Bregman Relatively Nonexpansive Mappings in Banach Spaces
}

\author{
Jiawei Chen, Zhongping Wan, Liuyang Yuan, and Yue Zheng
}

School of Mathematics and Statistics, Wuhan University, Wuhan, Hubei 430072, China

Correspondence should be addressed to Jiawei Chen, j.w.chen713@163.com

Received 7 April 2011; Accepted 19 May 2011

Academic Editor: Yonghong Yao

Copyright (c) 2011 Jiawei Chen et al. This is an open access article distributed under the Creative Commons Attribution License, which permits unrestricted use, distribution, and reproduction in any medium, provided the original work is properly cited.

We introduce a concept of weak Bregman relatively nonexpansive mapping which is distinct from Bregman relatively nonexpansive mapping. By using projection techniques, we construct several modification of Mann type iterative algorithms with errors and Halpern-type iterative algorithms with errors to find fixed points of weak Bregman relatively nonexpansive mappings and Bregman relatively nonexpansive mappings in Banach spaces. The strong convergence theorems for weak Bregman relatively nonexpansive mappings and Bregman relatively nonexpansive mappings are derived under some suitable assumptions. The main results in this paper develop, extend, and improve the corresponding results of Matsushita and Takahashi (2005) and Qin and Su (2007).

\section{Introduction}

Throughout this paper, without other specifications, we denote by $R$ the set of real numbers. Let $E$ be a real reflexive Banach space with the dual space $E^{*}$. The norm and the dual pair between $E^{*}$ and $E$ are denoted by $\|\cdot\|$ and $\langle\cdot, \cdot\rangle$, respectively. Let $f: E \rightarrow R \cup\{+\infty\}$ be proper convex and lower semicontinuous. The Fenchel conjugate of $f$ is the function $f^{*}: E^{*} \rightarrow$ $(-\infty,+\infty]$ defined by

$$
f^{*}(\xi)=\sup \{\langle\xi, x\rangle-f(x): x \in E\}
$$

We denote by $\operatorname{dom} f$ the domain of $f$, that is, $\operatorname{dom} f=\{x \in E: f(x)<+\infty\}$. Let $C$ be a nonempty closed and convex subset of $E$ and $T: C \rightarrow C$ a nonlinear mapping. Denote by $F(T)=\{x \in C: T x=x\}$, the set of fixed points of $T$. $T$ is said to be nonexpansive if $\|T x-T y\| \leq\|x-y\|$ for all $x, y \in C$. 
In 1967, Brègman [1] discovered an elegant and effective technique for the using of the so-called Bregman distance function $D_{f}$ (see, Section 2, Definition 2.1) in the process of designing and analyzing feasibility and optimization algorithms. This opened a growing area of research in which Bregman's technique is applied in various ways in order to design and analyze iterative algorithms for solving not only feasibility and optimization problems, but also algorithms for solving variational inequalities, for approximating equilibria, for computing fixed points of nonlinear mappings, and so on (see, e.g., [1-25], and the references therein).

Nakajo and Takahashi [26] introduced the following modification of the Mann iteration method for a nonexpansive mapping $T: C \rightarrow C$ in a Hilbert space $H$ as follows:

$$
\begin{gathered}
x_{0} \in C, \\
y_{n}=\alpha_{n} x_{n}+\left(1-\alpha_{n}\right) T x_{n}, \\
\bar{C}_{n}=\left\{z \in C:\left\|z-y_{n}\right\| \leq\left\|z-x_{n}\right\|\right\}, \\
\bar{Q}_{n}=\left\{z \in C:\left\langle x_{n}-z, x_{n}-x_{0}\right\rangle \leq 0\right\}, \\
x_{n+1}=\mathrm{P}_{\bar{C}_{n} \cap \bar{Q}_{n}} x_{0}, \quad \forall n \geq 0,
\end{gathered}
$$

where $\left\{\alpha_{n}\right\} \subset[0,1]$ and $P_{\bar{C}}$ is the metric projection from $H$ onto a closed and convex subset $C$ of $H$. They proved that $\left\{x_{n}\right\}$ generated by (1.2) converges strongly to a fixed point of $T$ under some suitable assumptions. Motivated by Nakajo and Takahashi [26], Matsushita and Takahashi [27] introduced the following modification of the Mann iteration method for a relatively nonexpansive mapping $T: C \rightarrow C$ in a Banach space $E$ as follows:

$$
\begin{gathered}
x_{0} \in C, \\
y_{n}=J^{-1}\left(\alpha_{n} J\left(x_{n}\right)+\left(1-\alpha_{n}\right) J\left(T x_{n}\right)\right), \\
\bar{C}_{n}=\left\{z \in C: \phi\left(z, y_{n}\right) \leq \phi\left(z, x_{n}\right)\right\}, \\
\bar{Q}_{n}=\left\{z \in C:\left\langle J\left(x_{n}\right)-J\left(x_{0}\right), x_{n}-z\right\rangle \leq 0\right\}, \\
x_{n+1}=\Pi_{\bar{C}_{n} n \bar{Q}_{n}} x_{0}, \quad \forall n \geq 0,
\end{gathered}
$$

where $\left\{\alpha_{n}\right\} \subset[0,1], \phi(y, x)=\|y\|^{2}-2\langle y, J(x)\rangle+\|x\|^{2}$ for all $x, y \in E, J$ is the duality mapping of $E$ and $\Pi_{C}$ is the generalized projection (see, e.g., $[2,3,28]$ ) from $E$ onto a closed and convex subset $C$ of $E$. They also proved that $\left\{x_{n}\right\}$ generated by (1.3) converges strongly to a fixed 
point of $T$ under some suitable assumptions. Martinez-Yanes and $\mathrm{Xu}$ [29] gave a Halperntype iterative algorithm for a nonexpansive mapping $T: C \rightarrow C$ as follows:

$$
\begin{gathered}
x_{0} \in C, \\
y_{n}=\beta_{n} x_{0}+\left(1-\beta_{n}\right) T x_{n}, \\
\bar{C}_{n}=\left\{z \in C:\left\|z-y_{n}\right\|^{2} \leq\left\|z-x_{n}\right\|^{2}+\beta_{n}\left(\left\|x_{0}\right\|^{2}+2\left\langle x_{n}-x_{0}, z\right\rangle\right)\right\}, \\
\bar{Q}_{n}=\left\{z \in C:\left\langle x_{n}-z, x_{n}-x_{0}\right\rangle \leq 0\right\}, \\
x_{n+1}=\mathrm{P}_{\bar{C}_{n} n \bar{Q}_{n}} x_{0}, \quad \forall n \geq 0,
\end{gathered}
$$

where $\left\{\beta_{n}\right\} \subset[0,1]$. They derived that $\left\{x_{n}\right\}$ generated by (1.3) converges strongly to a fixed point of $T$ under some suitable assumptions. Qin and $\mathrm{Su}$ [30] generalized the results of Martinez-Yanes and $\mathrm{Xu}$ [29] to a uniformly convex and uniformly smooth Banach space for a relatively nonexpansive mapping and proposed the following iterative algorithm:

$$
\begin{gathered}
x_{0} \in C, \\
y_{n}=J^{-1}\left(\beta_{n} J\left(x_{0}\right)+\left(1-\beta_{n}\right) J\left(T x_{n}\right)\right), \\
\bar{C}_{n}=\left\{z \in C: \phi\left(z, y_{n}\right) \leq \beta_{n} \phi\left(z, x_{0}\right)+\left(1-\beta_{n}\right) \phi\left(z, x_{n}\right)\right\}, \\
\bar{Q}_{n}=\left\{z \in C:\left\langle J\left(x_{n}\right)-J\left(x_{0}\right), x_{n}-z\right\rangle \leq 0\right\}, \\
x_{n+1}=\Pi_{\bar{C}_{n} \cap \bar{Q}_{n}} x_{0}, \quad \forall n \geq 0,
\end{gathered}
$$

where $\left\{\beta_{n}\right\} \subset[0,1], \Pi_{C}$ is the generalized projection (see, e.g., $[2,3,28]$ ) from $E$ onto a closed and convex subset $C$ of $E$. They also obtained that $\left\{x_{n}\right\}$ generated by (1.5) converges strongly to a fixed point of $T$ under some suitable assumptions. In 2003, Butnariu et al. [13] studied several notions of convex analysis: uniformly convexity at a point, total convexity at a point, uniformly convexity on bounded sets, and sequential consistency, which are useful in establishing convergence properties for fixed point and optimization algorithms in infinite dimensional Banach spaces. They established connections between these concepts and used these relations in order to obtain improved convergence results concerning the outer Bregman projection algorithm for solving convex feasibility problems and the generalized proximal point algorithm for optimization in Banach spaces. In 2006, Butnariu and Resmerita [14] presented a Bregman-type iterative algorithms and studied the convergence of the Bregman-type iterative method of solving operator equations. Resmerita [19] investigated the existence of totally convex functions in Banach spaces and, further, established continuity and stability properties of Bregman projections. Very recently, by using Bregman projection, Reich and Sabach [21] presented the following algorithms for finding common zeroes of 
maximal monotone operators $A_{i}: E \rightarrow 2^{E^{*}}(i=1,2, \ldots, N)$ in reflexive Banach space $E$ as follows:

$$
\begin{gathered}
x_{0} \in E, \\
y_{n}^{i}=\operatorname{Res}_{\lambda_{n}^{i}}^{f}\left(x_{n}+e_{n}^{i}\right), \\
C_{n}^{i}=\left\{z \in E: D_{f}\left(z, y_{n}^{i}\right) \leq D_{f}\left(z, x_{n}+e_{n}^{i}\right)\right\}, \\
C_{n}=\bigcap_{i=1}^{N} C_{n}^{i}, \\
Q_{n}=\left\{z \in E:\left\langle\nabla f\left(x_{0}\right)-\nabla f\left(x_{n}\right), z-x_{n}\right\rangle \leq 0\right\}, \\
x_{n+1}=\operatorname{proj}_{C_{n} \cap Q_{n}}^{f} x_{0}, \quad \forall n \geq 0, \\
x_{0} \in E, \\
\eta_{n}^{i}=\xi_{n}^{i}+\frac{1}{\lambda_{n}^{i}}\left(\nabla f\left(y_{n}^{i}\right)-\nabla f\left(x_{n}\right)\right), \quad \xi_{n}^{i} \in A_{i} y_{n}^{i}, \\
\omega_{n}^{i}=\nabla f^{*}\left(\lambda_{n}^{i} \eta_{n}^{i}+\nabla f\left(x_{n}\right)\right), \\
C_{n}^{i}=\left\{z \in E: D_{f}\left(z, y_{n}^{i}\right) \leq D_{f}\left(z, \omega_{n}^{i}\right)\right\}, \\
C_{n}=\bigcap_{i=1}^{N} C_{n}^{i}, \\
Q_{n}=\left\{z \in E:\left\langle\nabla f\left(x_{0}\right)-\nabla f\left(x_{n}\right), z-x_{n}\right\rangle \leq 0\right\}, \\
x_{n+1}=\operatorname{proj}_{C_{n} \cap Q_{n}}^{f} x_{0}, \quad \forall n \geq 0 .
\end{gathered}
$$

Further, under some suitable conditions, they obtained two strong convergence theorems of maximal monotone operators in reflexive Banach spaces. Reich and Sabach [22] studied the convergence of two iterative algorithms for finitely many Bregman strongly nonexpansive operators in Banach spaces and obtained two strong convergence theorems for finitely many Bregman strongly nonexpansive operators under some assumptions. In [24], Reich and Sabach proposed the following algorithms for finding common fixed points of finitely many Bregman firmly nonexpansive operators $T_{i}: C \rightarrow C(i=1,2, \ldots, N)$ in reflexive Banach space $E$ as follows: if $\bigcap_{i=1}^{N} F\left(T_{i}\right) \neq \emptyset$

$$
\begin{gathered}
x_{0} \in E, \\
Q_{0}^{i}=E, \quad i=1,2, \ldots, N, \\
y_{n}^{i}=T_{i}\left(x_{n}+e_{n}^{i}\right),
\end{gathered}
$$




$$
\begin{gathered}
Q_{n+1}^{i}=\left\{z \in Q_{n}^{i}:\left\langle\nabla f\left(x_{n}+e_{n}^{i}\right)-\nabla f\left(y_{n}^{i}\right), z-y_{n}^{i}\right\rangle \leq 0\right\}, \\
Q_{n}=\bigcap_{i=1}^{N} Q_{n^{\prime}}^{i} \\
x_{n+1}=\operatorname{proj}_{Q_{n+1}}^{f} x_{0}, \quad \forall n \geq 0 .
\end{gathered}
$$

Under some suitable conditions, they proved that the sequence $\left\{x_{n}\right\}$ generated by (1.8) converges strongly to $\bigcap_{i=1}^{N} F\left(T_{i}\right)$ and applied it to the solution of convex feasibility and equilibrium problems.

Inspired and motivated by the works, we introduce the concept of weak Bregman relatively nonexpansive mappings in reflexive Banach space and give an example to illustrate the existence of weak Bregman relatively nonexpansive mapping and the difference between weak Bregman relatively nonexpansive mapping and Bregman relatively nonexpansive mapping. Secondly, by using the conception of the Bregman projection (see, e.g., $[1,13,14]$ ), we construct several modification of Mann type iterative algorithms with errors and Halperntype iterative algorithms with errors to find fixed points of weak Bregman relatively nonexpansive mappings and Bregman relatively nonexpansive mappings in Banach spaces. The strong convergence theorems for weak Bregman relatively nonexpansive mappings and Bregman relatively nonexpansive mappings are derived under some suitable assumptions. Moreover, the convergence rate of our algorithms is faster than that of Matsushita and Takahashi [27] and Qin and Su [30]. The main results in this paper develop, extend, and improve the corresponding results in the literature.

\section{Preliminaries}

Let $C$ be a nonempty closed convex subset of a real reflexive Banach space $E$, and let $T: C \rightarrow$ $C$ be a nonlinear mapping. A point $\omega \in C$ is called an asymptotic fixed point of $T$ (see, e.g., $[2,3])$ if $C$ contains a sequence $\left\{x_{n}\right\}$ which converges weakly to $\omega$ such that $\lim _{n \rightarrow \infty} \| T x_{n}-$ $x_{n} \|=0$. A point $\omega \in C$ is called an strong asymptotic fixed point of $T$ (see, e.g., $[2,3]$ ) if $C$ contains a sequence $\left\{x_{n}\right\}$ which converges strongly to $\omega$ such that $\lim _{n \rightarrow \infty}\left\|T x_{n}-x_{n}\right\|=0$. We denote the sets of asymptotic fixed points and strong asymptotic fixed points of $T$ by $\widehat{F}(T)$ and $\widetilde{F}(T)$, respectively. When $\left\{x_{n}\right\}$ is a sequence in $E$, we denote strong convergence of $\left\{x_{n}\right\}$ to $x \in E$ by $x_{n} \rightarrow x$. For any $x \in \operatorname{int}(\operatorname{dom} f)$ and $y \in E$, the right-hand derivative of $f$ at $x$ in the direction $y$ defined by

$$
f^{0}(x, y):=\lim _{t \searrow 0} \frac{f(x+t y)-f(x)}{t}
$$

$f$ is called Gâteaux differentiable at $x$ if, for all $y \in E, \lim _{t \backslash 0}(f(x+t y)-f(x)) / t$ exists. In this case, $f^{0}(x, y)$ coincides with $\nabla f(x)$, the value of the gradient of $f$ at $x$. $f$ is called Gâteaux differentiable if it is Gâteaux differentiable for any $x \in \operatorname{int}(\operatorname{dom} f) . f$ is called Fréchet differentiable at $x$ if this limit is attained uniformly for $\|y\|=1$. We say $f$ is uniformly Fréchet differentiable on a subset $C$ of $E$ if the limit is attained uniformly for $x \in C$ and $\|y\|=1$. 
Legendre function $f: E \rightarrow(-\infty,+\infty$ ] is defined in [7]. From [7], if $E$ is a reflexive Banach space, then $f$ is Legendre if and only if it satisfies the following conditions (L1) and (L2):

(L1) the interior of the domain of $f, \operatorname{int}(\operatorname{dom} f)$, is nonempty, $f$ is Gâteaux differentiable on $\operatorname{int}(\operatorname{dom} f)$, and $\operatorname{dom} f=\operatorname{int}(\operatorname{dom} f)$,

(L2) the interior of the domain of $f^{*}, \operatorname{int}\left(\operatorname{dom} f^{*}\right)$, is nonempty, $f^{*}$ is Gâteaux differentiable on $\operatorname{int}\left(\operatorname{dom} f^{*}\right)$, and $\operatorname{dom} f^{*}=\operatorname{int}\left(\operatorname{dom} f^{*}\right)$. implies

Since $E$ is reflexive, we know that $(\partial f)^{-1}=\partial f^{*}$ (see, e.g., [31]). This, by (L1) and (L2),

$$
\begin{gathered}
\nabla f=\left(\nabla f^{*}\right)^{-1}, \quad \operatorname{ran} \nabla f=\operatorname{dom} \nabla f^{*}=\operatorname{int}\left(\operatorname{dom} f^{*}\right), \\
\operatorname{ran} \nabla f^{*}=\operatorname{dom} \nabla f=\operatorname{int}(\operatorname{dom} f) .
\end{gathered}
$$

By Theorem 5.4 [7], conditions (L1) and (L2) also yield that the functions $f$ and $f^{*}$ are strictly convex on the interior of their respective domains. From now on, we assume that the convex function $f: E \rightarrow(-\infty,+\infty]$ is Legendre.

We first recall some definitions and lemmas which are needed in our main results.

Definition 2.1 (see $[1,13]$ ). Let $f: E \rightarrow(-\infty,+\infty]$ be a Gâteaux differentiable and convex function. The function $D_{f}: \operatorname{dom} f \times \operatorname{int}(\operatorname{dom} f) \rightarrow[0,+\infty)$, defined by

$$
D_{f}(y, x):=f(y)-f(x)-\langle\nabla f(x), y-x\rangle
$$

is called the Bregman distance with respect to $f$.

Remark 2.2 (see [24]). The Bregman distance has the following properties:

(i) the three point identity, for any $x \in \operatorname{dom} f$ and $y, z \in \operatorname{int}(\operatorname{dom} f)$,

$$
D_{f}(x, y)+D_{f}(y, z)-D_{f}(x, z)=\langle\nabla f(z)-\nabla f(y), x-y\rangle,
$$

(ii) the four point identity, for any $y, \omega \in \operatorname{dom} f$ and $x, z \in \operatorname{int}(\operatorname{dom} f)$,

$$
D_{f}(y, x)-D_{f}(y, z)-D_{f}(\omega, x)+D_{f}(\omega, z)=\langle\nabla f(z)-\nabla f(x), y-\omega\rangle .
$$

Definition 2.3 (see [1]). Let $f: E \rightarrow(-\infty,+\infty]$ be a Gâteaux differentiable and convex function. The Bregman projection of $x \in \operatorname{int}(\operatorname{dom} f)$ onto the nonempty closed and convex set $C \subset \operatorname{dom} f$ is the necessarily unique vector $\operatorname{proj}_{C}^{f}(x) \in C$ satisfying

$$
D_{f}\left(\operatorname{proj}_{C}^{f}(x), x\right)=\inf \left\{D_{f}(y, x): y \in C\right\}
$$


Remark 2.4. (i) If $E$ is a Hilbert space and $f(y)=(1 / 2)\|x\|^{2}$ for all $x \in E$, then the Bregman projection $\operatorname{proj}_{C}^{f}(x)$ is reduced to the metric projection of $x$ onto $C$.

(ii) If $E$ is a smooth Banach space and $f(y)=(1 / 2)\|x\|^{2}$ for all $x \in E$, then the Bregman projection $\operatorname{proj}_{C}^{f}(x)$ is reduced to the generalized projection $\Pi_{C}(x)$ (see, e.g. [3]) which defined by

$$
\phi\left(\Pi_{C}(x), x\right)=\min _{y \in C} \phi(y, x)
$$

where $\phi(y, x)=\|y\|^{2}-2\langle y, J(x)\rangle+\|x\|^{2}, J$ is the normalized duality mapping from $\mathrm{E}$ to $2^{E^{*}}$. Definition 2.5 (see[12, 21]). Let $C$ be a nonempty closed and convex set of $\operatorname{dom} f$. The operator $T: C \rightarrow \operatorname{int}(\operatorname{dom} f)$ with $F(T) \neq \emptyset$ is called:

(i) quasi-Bregman nonexpansive if

$$
D_{f}(u, T x) \leq D_{f}(u, x), \quad \forall x \in C, u \in F(T)
$$

(ii) Bregman relatively nonexpansive if

$$
D_{f}(u, T x) \leq D_{f}(u, x), \quad \forall x \in C, u \in F(T)
$$

and $\widehat{F}(T)=F(T)$,

(iii) Bregman firmly nonexpansive if

$$
\langle\nabla f(T x)-\nabla f(T y), T x-T y\rangle \leq\langle\nabla f(x)-\nabla f(y), T x-T y\rangle, \quad \forall x, y \in C,
$$

or equivalently

$$
\begin{gathered}
D_{f}(T x, T y)+D_{f}(T y, T x)+D_{f}(T x, x)+D_{f}(T y, y) \\
\leq D_{f}(T x, y)+D_{f}(T y, x), \quad \forall x, y \in C
\end{gathered}
$$

Definition 2.6. Let $C$ be a nonempty closed and convex set of $\operatorname{dom} f$. The operator $T: C \rightarrow$ $\operatorname{int}(\operatorname{dom} f)$ with $F(T) \neq \emptyset$ is called weak Bregman relatively nonexpansive if $\widetilde{F}(T)=F(T)$ and

$$
D_{f}(u, T x) \leq D_{f}(u, x), \quad \forall x \in C, u \in F(T)
$$

Remark 2.7. It is easy to see that each nonexpansive mapping $T$ is quasi-Bregman nonexpansive mapping with respect to $f(x)=(1 / 2)\|x\|^{2}$ for all $x \in E$. Moreover, every relatively nonexpansive mapping $T$ also is Bregman relatively nonexpansive mapping, where 
$T$ is called relatively nonexpansive mapping (see, e.g., [32]) if the following conditions are satisfied:

$$
\widehat{F}(T)=F(T) \neq \emptyset, \quad \phi(u, T x) \leq \phi(u, x), \quad \forall x \in C, u \in F(T) .
$$

Now, we give an example which is weak Bregman relatively nonexpansive mapping but not Bregman relatively nonexpansive mapping.

Example 2.8. Let $E=l^{2}, f(x)=(1 / 2)\|x\|^{2}$ for all $x \in E$, where

$$
l^{2}=\left\{\xi=\left(\xi_{1}, \xi_{2}, \ldots, \xi_{n}, \ldots\right): \sum_{n=1}^{\infty}\left|\xi_{n}\right|^{2}<\infty\right\}, \quad\|\xi\|=\left(\sum_{n=1}^{\infty}\left|\xi_{n}\right|^{2}\right)^{1 / 2}, \quad \forall \xi \in l^{2},
$$

and for any $\xi=\left(\xi_{1}, \xi_{2}, \ldots, \xi_{n}, \ldots\right), \mu=\left(\mu_{1}, \mu_{2}, \ldots, \mu_{n}, \ldots\right) \in E,\langle\xi, \mu\rangle=\sum_{n=1}^{\infty} \xi_{n} \mu_{n}$. It is well known that $l^{2}$ is a Hilbert space. Let $\left\{x_{n}\right\} \subset E$ be a sequence defined by $x_{0}=(1,0,0$, $0, \ldots), x_{1}=(1,1,0,0, \ldots), x_{2}=(1,0,1,0, \ldots), \ldots, x_{n}=\left(\xi_{n, 1}, \ldots, \xi_{n, k}, \ldots\right), \ldots$, where

$$
\xi_{n, k}= \begin{cases}1, & \text { if } k=1, n+1 \\ 0, & \text { otherwise }\end{cases}
$$

for all $n \geq 0$.

Define a mapping $T: E \rightarrow E$ by

$$
T(x)= \begin{cases}\frac{n x_{n}}{n+1}, & \text { if } x=x_{n}(\exists n \geq 1) \\ -x, & \text { if } x \neq x_{n}(\forall n \geq 1)\end{cases}
$$

for all $n \geq 0$. It is easy to see that $F(T)=\{0\}$, and so, $\left\{x_{n}\right\}$ converges weakly to $x_{0}$. Indeed, for any $g=\left(\zeta_{1}, \zeta_{2} \ldots, \zeta_{k}, \ldots\right) \in E$, we have

$$
g\left(x_{n}-x_{0}\right)=\left\langle g, x_{n}-x_{0}\right\rangle=\sum_{k=2}^{\infty} \zeta_{k} \xi_{n, k}=\zeta_{n+1}
$$

From $\sum_{n=1}^{\infty}\left|\zeta_{n}\right|^{2}<\infty$, it shows that $\lim _{n \rightarrow \infty} \zeta_{n+1}=0$. Moreover,

$$
\lim _{n \rightarrow \infty} g\left(x_{n}-x_{0}\right)=\lim _{n \rightarrow \infty} \zeta_{n+1}=0
$$

Next, for any $m \neq n$, one has $\left\|x_{n}-x_{m}\right\|=\sqrt{2} \neq 0$; that is, $\left\{x_{n}\right\}$ is not a Cauchy sequence. Owing to $\left\|T x_{n}-x_{n}\right\|=\left\|x_{n}\right\| /(n+1)$, we obtain

$$
\lim _{n \rightarrow \infty}\left\|T x_{n}-x_{n}\right\|=0
$$


Then, $x_{0}$ is an asymptotic fixed point of $T$, but $x_{0} \notin F(T)=\{0\}$. So, $T$ is not Bregman relatively nonexpansive mapping.

For any strong convergent sequence $\left\{y_{n}\right\} \subset l^{2}$ such that $y_{n} \rightarrow y_{0}$ and $\left\|T y_{n}-y_{n}\right\| \rightarrow 0$ as $n \rightarrow \infty$. Then, there exists a sufficiently large nature number $M$ such that $y_{n} \neq x_{m}$ for any $n, m>M$. Thus, $T y_{n}=-y_{n}$ for $n>M$, which implies that $2 y_{n} \rightarrow 0$ and $y_{n} \rightarrow y_{0}=0$ as $n \rightarrow \infty$. That is, $y_{0}=0$ is a strong asymptotic fixed point of $T$, and so, $\widetilde{F}(T)=F(T)=\{0\}$. Since

$$
\begin{aligned}
D_{f}(0, T x) & =f(0)-f(T x)-\langle\nabla f(T x), 0-T x\rangle=-\frac{1}{2}\|T x\|^{2}+\langle T x, T x\rangle=\frac{1}{2}\|T x\|^{2} \\
& \leq \frac{1}{2}\|x\|^{2}=f(0)-f(x)-\langle\nabla f(x), 0-x\rangle=D_{f}(0, x), \quad x \in E .
\end{aligned}
$$

Therefore, $T$ is a weak Bregman relatively nonexpansive mapping.

Definition 2.9 (see [12]). Let $f: E \rightarrow(-\infty,+\infty]$ be a convex and Gâteaux differentiable function. $f$ is called:

(i) totally convex at $x \in \operatorname{int}(\operatorname{dom} f)$ if its modulus of total convexity at $x$; that is, the function $v_{f}: \operatorname{int}(\operatorname{dom} f) \times[0,+\infty) \rightarrow[0,+\infty)$ defined by

$$
v_{f}(x, t):=\inf \left\{D_{f}(y, x): y \in \operatorname{dom} f,\|y-x\|=t\right\}
$$

is positive whenever $t>0$,

(ii) totally convex if, it is totally convex at every point $x \in \operatorname{int}(\operatorname{dom} f)$,

(iii) totally convex on bounded sets if $v_{f}(B, t)$ is positive for any nonempty bounded subset $B$ of $E$ and $t>0$, where the modulus of total convexity of the function $f$ on the set $B$ is the function $v_{f}: \operatorname{int}(\operatorname{dom} f) \times[0,+\infty) \rightarrow[0,+\infty)$ defined by

$$
v_{f}(B, t):=\inf \left\{v_{f}(x, t): x \in B \cap \operatorname{dom} f\right\} .
$$

Definition 2.10 (see $[12,21])$. The function $f: E \rightarrow(-\infty,+\infty]$ is called:

(i) cofinite if $\operatorname{dom} f^{*}=E^{*}$,

(ii) sequentially consistent if, for any two sequences $\left\{x_{n}\right\}$ and $\left\{y_{n}\right\}$ in $E$ such that the first is bounded, and

$$
\lim _{n \rightarrow \infty} D_{f}\left(y_{n}, x_{n}\right)=0 \Longrightarrow \lim _{n \rightarrow \infty}\left\|y_{n}-x_{n}\right\|=0
$$

Lemma 2.11 (see [21, Proposition 2.3]). If $f: E \rightarrow(-\infty,+\infty]$ is Fréchet differentiable and totally convex, then $f$ is cofinite. 
Lemma 2.12 (see [14, Theorem 2.10]). Let $f: E \rightarrow(-\infty,+\infty]$ be a convex function whose domain contains at least two points. Then, the following statements hold:

(i) $f$ is sequentially consistent if and only if it is totally convex on bounded sets,

(ii) if $f$ is lower semicontinuous, then $f$ is sequentially consistent if and only if it is uniformly convex on bounded sets,

(iii) if $f$ is uniformly strictly convex on bounded sets, then it is sequentially consistent and the converse implication holds when $f$ is lower semicontinuous, Fréchet differentiable on its domain, and the Fréchet derivative $f^{\prime}$ is uniformly continuous on bounded sets.

Lemma 2.13 (see [20, Proposition 2.1]). Let $f: E \rightarrow R$ be a uniformly Fréchet differentiable and bounded on bounded subsets of $E$. Then, $\nabla f$ is uniformly continuous on bounded subsets of $E$ from the strong topology of $E$ to the strong topology of $E^{*}$.

Lemma 2.14 (see [21, Lemma 3.1]). Let $f: E \rightarrow R$ be a Gâteaux differentiable and totally convex function. If $x_{0} \in E$ and the sequence $\left\{D_{f}\left(x_{n}, x_{0}\right)\right\}_{n=1}^{\infty}$ is bounded, then the sequence $\left\{x_{n}\right\}_{n=1}^{\infty}$ is also bounded.

Lemma 2.15 (see [21, Proposition 2.2]). Let $f: E \rightarrow R$ be a Gâteaux differentiable and totally convex function, $x_{0} \in E$, and let $C$ be a nonempty closed convex subset of $E$. Suppose that the sequence $\left\{x_{n}\right\}_{n=1}^{\infty}$ is bounded and any weak subsequential limit of $\left\{x_{n}\right\}_{n=1}^{\infty}$ belongs to C. If $D_{f}\left(x_{n}, x_{0}\right) \leq$ $D_{f}\left(\operatorname{proj}_{C}^{f}\left(x_{0}\right), x_{0}\right)$ for any $n \in N$, then $\left\{x_{n}\right\}_{n=1}^{\infty}$ converges strongly to $\operatorname{proj}_{C}^{f}\left(x_{0}\right)$.

In [23], Reich and Sabach proved the following result.

Lemma 2.16 (see [23, Lemma 15.5]). Let $f: E \rightarrow(-\infty,+\infty]$ be a Legendre function. Let $C$ be a nonempty closed convex subset of $\operatorname{int}(\operatorname{dom} f)$ and $T: C \rightarrow C$ a Bregman firmly nonexpansive mapping with respect to $f$. Then, $F(T)$ is closed and convex.

Motivated by Lemma 2.16, we get the similar result for quasi-Bregman nonexpansive mapping.

Proposition 2.17. Let $f: E \rightarrow(-\infty,+\infty]$ be a Legendre function. Let $C$ be a nonempty closed convex subset of $\operatorname{int}(\operatorname{dom} f$ ) and $T: C \rightarrow C$ a quasi-Bregman nonexpansive mapping with respect to $f$. Then, $F(T)$ is closed and convex.

Proof. Without loss of generality, set $F(T)$ is nonempty. Firstly, we show that $F(T)$ is closed. Let $\left\{x_{n}\right\}_{n=0}^{\infty}$ be a sequence in $F(T)$ such that $x_{n} \rightarrow \bar{x}$. By the definition of quasi-Bregman nonexpansive mapping, we have

$$
D_{f}\left(x_{n}, T \bar{x}\right) \leq D_{f}\left(x_{n}, \bar{x}\right), \quad n \geq 0 .
$$

Since $f: E \rightarrow(-\infty,+\infty]$ is a Legendre function, $f$ is continuous at $\bar{x} \in C \subset \operatorname{int}(\operatorname{dom} f)$. Then, from the definition of Bregman distance,

$$
\begin{aligned}
& \lim _{n \rightarrow \infty} D_{f}\left(x_{n}, T \bar{x}\right)=D_{f}(\bar{x}, T \bar{x}), \\
& \lim _{n \rightarrow \infty} D_{f}\left(x_{n}, \bar{x}\right)=D_{f}(\bar{x}, \bar{x})=0 .
\end{aligned}
$$


From (2.24) and (2.25), it follows that $D_{f}(\bar{x}, T \bar{x})=0$, and so, from [7, Lemma 7.3(vi), page 642], $T \bar{x}=\bar{x}$. Therefore, $\bar{x} \in F(T)$, and so, $F(T)$ is closed.

We now show that $F(T)$ is convex. For any $x, y \in F(T)$ and $t \in(0,1)$, it yields that $z=t x+(1-t) y \in C$. From the definition of quasi-Bregman nonexpansive mapping, it follows that

$$
\begin{aligned}
D_{f}(z, T z) & =f(z)-f(T z)-\langle\nabla f(T z), t x+(1-t) y-T(t x+(1-t) y)\rangle \\
& =f(z)+t D_{f}(x, T z)+(1-t) D_{f}(y, T z)-t f(x)-(1-t) f(y) \\
& \leq f(z)+t D_{f}(x, z)+(1-t) D_{f}(y, z)-t f(x)-(1-t) f(y) \\
& =\langle\nabla f(z), z-t x-(1-t) y\rangle=0 .
\end{aligned}
$$

Again, from [7, Lemma 7.3(vi), page 642], we get $T z=z$. Therefore, $F(T)$ is convex. This completes the proof.

From the definitions of Bregman distance and the Fenchel conjugate of $f$, we have the following result.

Lemma 2.18. Let $f: E \rightarrow(-\infty,+\infty]$ be a Gâteaux differentiable and proper convex lower semicontinuous. Then, for all $z \in E$,

$$
D_{f}\left(z, \nabla f^{*}\left(\sum_{i=1}^{N} t_{i} \nabla f\left(x_{i}\right)\right)\right) \leq \sum_{i=1}^{N} t_{i} D_{f}\left(z, x_{i}\right)
$$

where $\left\{x_{i}\right\}_{i=1}^{N} \subset E$ and $\left\{t_{i}\right\}_{i=1}^{N} \subset(0,1)$ with $\sum_{i=1}^{N} t_{i}=1$.

Lemma 2.19 (see [14, Corollary 4.4]). Let $f: E \rightarrow(-\infty,+\infty]$ be a Gâteaux differentiable and totally convex on $\operatorname{int}(\operatorname{dom} f)$. Let $x \in \operatorname{int}(\operatorname{dom} f)$ and $C \subset \operatorname{int}(\operatorname{dom} f)$ a nonempty closed convex set. If $\widehat{x} \in C$, then the following statements are equivalent:

(i) the vector $\hat{x}$ is the Bregman projection of $x$ onto $C$ with respect to $f$,

(ii) the vector $\hat{x}$ is the unique solution of the variational inequality

$$
\langle\nabla f(x)-\nabla f(z), z-y\rangle \geq 0, \quad \forall y \in C,
$$

(iii) the vector $\hat{x}$ is the unique solution of the inequality

$$
D_{f}(y, z)+D_{f}(z, x) \leq D_{f}(y, x), \quad \forall y \in C
$$

\section{Main Results}

In this section, we introduce several modification of Mann-type iterative algorithms with errors and Halpern-type iterative algorithms with errors to find fixed points of weak Bregman 
relatively nonexpansive mappings and Bregman relatively nonexpansive mappings in Banach spaces. The strong convergence theorems for weak Bregman relatively nonexpansive mappings and Bregman relatively nonexpansive mappings are proved under some suitable conditions.

Theorem 3.1. Let $C$ be a nonempty closed convex subset of a real reflexive Banach space $E$ and $f$ : $E \rightarrow R$ a Legendre function which is bounded, uniformly Fréchet differentiable, and totally convex on bounded subset of $E$, and let $T: C \rightarrow C$ be a weak Bregman relatively nonexpansive mapping such that $F(T) \neq \emptyset$. Define a sequence $\left\{x_{n}\right\}$ in $C$ by the following algorithm:

$$
\begin{gathered}
x_{0} \in C, \quad Q_{0}=C, \\
z_{n}=\nabla f^{*}\left(\beta_{n} \nabla f\left(T\left(x_{n}+e_{n}\right)\right)+\left(1-\beta_{n}\right) \nabla f\left(x_{n}+e_{n}\right)\right), \\
y_{n}=\nabla f^{*}\left(\alpha_{n} \nabla f\left(x_{n}+e_{n}\right)+\left(1-\alpha_{n}\right) \nabla f\left(z_{n}\right)\right), \\
C_{n}=\left\{z \in C_{n-1} \cap Q_{n-1}: D_{f}\left(z, y_{n}\right) \leq D_{f}\left(z, x_{n}+e_{n}\right)\right\}, \\
C_{0}=\left\{z \in C: D_{f}\left(z, y_{0}\right) \leq D_{f}\left(z, x_{0}\right)\right\}, \\
Q_{n}=\left\{z \in C_{n-1} \cap Q_{n-1}:\left\langle\nabla f\left(x_{0}\right)-\nabla f\left(x_{n}\right), z-x_{n}\right\rangle \leq 0\right\}, \\
x_{n+1}=\operatorname{proj}_{C_{n} \cap Q_{n}}^{f} x_{0}, \quad \forall n \geq 0,
\end{gathered}
$$

where $\left\{\alpha_{n}\right\},\left\{\beta_{n}\right\} \subset[0,1]$ such that $\lim _{n \rightarrow \infty}\left(1-\alpha_{n}\right) \beta_{n}>0$, and $\left\{e_{n}\right\}$ is an error sequence in $E$ with $e_{n} \rightarrow 0$ as $n \rightarrow \infty$. Then, the sequences $\left\{x_{n}\right\}$ and $\left\{y_{n}\right\}$ converge strongly to the point $\operatorname{proj}_{F(T)}^{f}\left(x_{0}\right)$, where $\operatorname{proj}_{F(T)}^{f}\left(x_{0}\right)$ is the Bregman projection of $C$ onto $F(T)$.

Proof. By Proposition 2.17, it follows that $F(T)$ is a nonempty closed and convex subset of $E$. It is easy to verify that $C_{0}, C_{1}, Q_{0}$, and $Q_{1}$ are closed and convex. Suppose that $C_{k}$ and $Q_{k}(k \geq 1)$ are closed and convex. Then, $C_{k} \cap Q_{k}$ is closed and convex. For any $z \in C_{k+1}, y \in Q_{k+1}$,

$$
\begin{aligned}
& D_{f}\left(z, y_{k+1}\right) \leq D_{f}\left(z, x_{k+1}+e_{k+1}\right) \\
& \Longleftrightarrow f(z)-f\left(y_{k+1}\right)-\left\langle\nabla f\left(y_{k+1}\right), z-y_{k+1}\right\rangle \\
& \quad \leq f(z)-f\left(x_{k+1}+e_{k+1}\right)-\left\langle\nabla f\left(x_{k+1}+e_{k+1}\right), z-\left(x_{k+1}+e_{k+1}\right)\right\rangle \\
& \Longleftrightarrow\left\langle\nabla f\left(x_{k+1}+e_{k+1}\right), z-\left(x_{k+1}+e_{k+1}\right)\right\rangle-\left\langle\nabla f\left(y_{k+1}\right), z-y_{k+1}\right\rangle \\
& \quad \leq f\left(y_{k+1}\right)-f\left(x_{k+1}+e_{k+1}\right) \\
& \Longleftrightarrow\left\langle\nabla f\left(x_{k+1}+e_{k+1}\right)-\nabla f\left(y_{k+1}\right), z-y_{k+1}\right\rangle \\
& \quad \leq f\left(y_{k+1}\right)-f\left(x_{k+1}+e_{k+1}\right)-\left\langle\nabla f\left(x_{k+1}+e_{k+1}\right), y_{k+1}-\left(x_{k+1}+e_{k+1}\right)\right\rangle \\
& \Longleftrightarrow\left\langle\nabla f\left(x_{k+1}+e_{k+1}\right)-\nabla f\left(y_{k+1}\right), z-y_{k+1}\right\rangle \leq D_{f}\left(y_{k+1}, x_{k+1}+e_{k+1}\right), \\
& \left\langle\nabla f\left(x_{0}\right)-\nabla f\left(x_{k}\right), y-x_{k}\right\rangle \leq 0,
\end{aligned}
$$


which implies that $C_{k+1}$ and $Q_{k+1}$ are closed and convex. As a consequence, $C_{n}$ and $Q_{n}$ are closed and convex for all $n \geq 0$. Taking $p \in F(T)$ arbitrarily,

$$
\begin{aligned}
D_{f} & \left(p, y_{n}\right) \\
& =D_{f}\left(p, \nabla f^{*}\left(\alpha_{n} \nabla f\left(x_{n}+e_{n}\right)+\left(1-\alpha_{n}\right) \nabla f\left(z_{n}\right)\right)\right) \\
& \leq \alpha_{n} D_{f}\left(p, x_{n}+e_{n}\right)+\left(1-\alpha_{n}\right) D_{f}\left(p, z_{n}\right) \\
& =\alpha_{n} D_{f}\left(p, x_{n}+e_{n}\right)+\left(1-\alpha_{n}\right) D_{f}\left(p, \nabla f^{*}\left(\beta_{n} \nabla f\left(T\left(x_{n}+e_{n}\right)\right)+\left(1-\beta_{n}\right) \nabla f\left(x_{n}+e_{n}\right)\right)\right) \\
& \leq \alpha_{n} D_{f}\left(p, x_{n}+e_{n}\right)+\left(1-\alpha_{n}\right)\left[\left(1-\beta_{n}\right) D_{f}\left(p, x_{n}+e_{n}\right)+\beta_{n} D_{f}\left(p, T\left(x_{n}+e_{n}\right)\right)\right] \\
& \leq \alpha_{n} D_{f}\left(p, x_{n}+e_{n}\right)+\left(1-\alpha_{n}\right)\left[\left(1-\beta_{n}\right) D_{f}\left(p, x_{n}+e_{n}\right)+\beta_{n} D_{f}\left(p, x_{n}+e_{n}\right)\right] \\
& =D_{f}\left(p, x_{n}+e_{n}\right),
\end{aligned}
$$

that is, $p \in C_{n}$, and so, $F(T) \subset C_{n}$ for all $n \geq 0$. We now show that $F(T) \subset Q_{n}$ for all $n \geq 0$. Clearly, $F(T) \subset Q_{0}=C$. Assume that $F(T) \subset Q_{k}$ for all $k \geq 0$. Note that $x_{k+1}=\operatorname{proj}_{C_{k} \cap Q_{k}}^{f}\left(x_{0}\right)$, and we have

$$
\left\langle\nabla f\left(x_{0}\right)-\nabla f\left(x_{k+1}\right), x_{k+1}-z\right\rangle \geq 0, \quad z \in C_{k} \cap Q_{k} .
$$

Therefore,

$$
\left\langle\nabla f\left(x_{0}\right)-\nabla f\left(x_{k+1}\right), x_{k+1}-p\right\rangle \geq 0, \quad p \in F \subset C_{k} \cap Q_{k},
$$

which yields that $p \in Q_{k+1}$. Then, $F(T) \subset Q_{n}$ for all $n \geq 0$. Consequently, $F(T) \subset C_{n} \cap Q_{n}$ and $C_{n} \cap Q_{n}$ is nonempty closed and convex for all $n \geq 0$. Moreover, $\left\{x_{n}\right\}$ is well defined.

Secondly, we show that $\left\{x_{n}\right\}$ is a Cauchy sequence and bounded. Since

$$
\left\langle\nabla f\left(x_{0}\right)-\nabla f\left(x_{n}\right), z-x_{n}\right\rangle \leq 0, \quad \forall z \in Q_{n}
$$

it follows that $x_{n}=\operatorname{proj}_{Q_{n}}^{f}\left(x_{0}\right)$. Therefore, by $x_{n+1}=\operatorname{proj}_{C_{n} \cap Q_{n}}^{f}\left(x_{0}\right) \in Q_{n}$,

$$
D_{f}\left(x_{n}, x_{0}\right) \leq D_{f}\left(x_{n+1}, x_{0}\right)
$$

Taking $p \in F(T)$ arbitrarily. From Lemma 2.19, it yields that

$$
D_{f}\left(p, \operatorname{proj}_{Q_{n}}^{f}\left(x_{0}\right)\right)+D_{f}\left(\operatorname{proj}_{Q_{n}}^{f}\left(x_{0}\right), x_{0}\right) \leq D_{f}\left(p, x_{0}\right) .
$$

Moreover, one has

$$
D_{f}\left(x_{n}, x_{0}\right) \leq D_{f}\left(p, x_{0}\right)-D_{f}\left(p, x_{n}\right) \leq D_{f}\left(p, x_{0}\right) .
$$


Hence, $\left\{D_{f}\left(x_{n}, x_{0}\right)\right\}$ is bounded and so $\left\{x_{n}\right\},\left\{y_{n}\right\}$, and $\left\{z_{n}\right\}$ are also bounded. From (3.7), it shows that $\lim _{n \rightarrow \infty} D_{f}\left(x_{n}, x_{0}\right)$ exists. In the light of $x_{m} \in Q_{m-1} \subset Q_{n}$ for any $m>n$, by Lemma 2.19,

$$
D_{f}\left(x_{m}, \operatorname{proj}_{Q_{n}}^{f}\left(x_{0}\right)\right)+D_{f}\left(\operatorname{proj}_{Q_{n}}^{f}\left(x_{0}\right), x_{0}\right) \leq D_{f}\left(x_{m}, x_{0}\right),
$$

that is,

$$
D_{f}\left(x_{m}, x_{n}\right) \leq D_{f}\left(x_{m}, x_{0}\right)-D_{f}\left(x_{n}, x_{0}\right)
$$

Consequently, one has

$$
\lim _{n \rightarrow \infty} D_{f}\left(x_{m}, x_{n}\right)=0
$$

Since $f$ is totally convex on bounded subsets of $E$, by Lemma 2.12 and (3.12), we have

$$
\lim _{n \rightarrow \infty}\left\|x_{m}-x_{n}\right\|=0
$$

Thus, $\left\{x_{n}\right\}$ is a Cauchy sequence, and so,

$$
\lim _{n \rightarrow \infty}\left\|x_{n+1}-x_{n}\right\|=0
$$

Since $e_{n} \rightarrow 0$ as $n \rightarrow \infty$, one has

$$
\lim _{n \rightarrow \infty}\left\|\left(x_{n+1}+e_{n+1}\right)-\left(x_{n}+e_{n}\right)\right\|=0, \quad \lim _{n \rightarrow \infty}\left\|x_{n+1}-\left(x_{n}+e_{n}\right)\right\|=0 .
$$

Let $x_{n} \rightarrow \bar{\omega} \in C$. Then, $x_{n}+e_{n} \rightarrow \bar{\omega}$.

Thirdly, we show that $\left\{x_{n}\right\}$ converges strongly to a point of $F(T)$. Since $f$ is uniformly Fréchet differentiable on bounded subsets of $E$, from Lemma 2.12, $\nabla f$ is norm-to-norm uniformly continuous on bounded subsets of $E$. So, by (3.15),

$$
\lim _{n \rightarrow \infty}\left\|\nabla f\left(x_{n+1}\right)-\nabla f\left(x_{n}+e_{n}\right)\right\|=0 .
$$

It follows from $x_{n+1} \in C_{n}$ that

$$
D_{f}\left(x_{n+1}, y_{n}\right) \leq D_{f}\left(x_{n+1}, x_{n}+e_{n}\right) \text {. }
$$

By the uniformly Fréchet differentiable of $f$ on bounded subsets of $E, f$ is also uniformly continuous on bounded subsets of $E$. Hence, from (3.12) and $\lim _{n \rightarrow \infty} e_{n}=0$,

$$
\lim _{n \rightarrow \infty} D_{f}\left(x_{n+1}, x_{n}+e_{n}\right)=\lim _{n \rightarrow \infty}\left(f\left(x_{n+1}\right)-f\left(x_{n}+e_{n}\right)-\left\langle\nabla f\left(x_{n}+e_{n}\right), x_{n+1}-\left(x_{n}+e_{n}\right)\right\rangle\right)=0
$$


International Journal of Mathematics and Mathematical Sciences

As a consequence, $\lim _{n \rightarrow \infty} D_{f}\left(x_{n+1}, y_{n}\right)=0$ and so, $\lim _{n \rightarrow \infty}\left\|x_{n+1}-y_{n}\right\|=0$. Moreover, one has

$$
\lim _{n \rightarrow \infty}\left\|\nabla f\left(x_{n+1}\right)-\nabla f\left(y_{n}\right)\right\|=0
$$

Since $\left\|x_{n}-y_{n}\right\| \leq\left\|x_{n}-x_{n+1}\right\|+\left\|x_{n+1}-y_{n}\right\|,\left\|x_{n}-y_{n}\right\| \rightarrow 0$ and $y_{n} \rightarrow \bar{\omega}$ as $n \rightarrow \infty$. Noticing that

$$
\begin{aligned}
&\left\|\nabla f\left(x_{n+1}\right)-\nabla f\left(y_{n}\right)\right\| \\
&=\left\|\nabla f\left(x_{n+1}\right)-\left(\alpha_{n} \nabla f\left(x_{n}+e_{n}\right)+\left(1-\alpha_{n}\right) \nabla f\left(z_{n}\right)\right)\right\| \\
& \geq\left(1-\alpha_{n}\right)\left\|\nabla f\left(x_{n+1}\right)-\nabla f\left(z_{n}\right)\right\|-\alpha_{n}\left\|\nabla f\left(x_{n+1}\right)-\nabla f\left(x_{n}+e_{n}\right)\right\| \\
&=\left(1-\alpha_{n}\right)\left\|\nabla f\left(x_{n+1}\right)-\left(\beta_{n} \nabla f\left(T\left(x_{n}+e_{n}\right)\right)+\left(1-\beta_{n}\right) \nabla f\left(x_{n}+e_{n}\right)\right)\right\| \\
&-\alpha_{n}\left\|\nabla f\left(x_{n+1}\right)-\nabla f\left(x_{n}+e_{n}\right)\right\| \\
& \geq-\alpha_{n}\left\|\nabla f\left(x_{n+1}\right)-\nabla f\left(x_{n}+e_{n}\right)\right\|+\left(1-\alpha_{n}\right) \beta_{n}\left\|\nabla f\left(x_{n+1}\right)-\nabla f\left(T\left(x_{n}+e_{n}\right)\right)\right\| \\
&-\left(1-\alpha_{n}\right)\left(1-\beta_{n}\right)\left\|\nabla f\left(x_{n+1}\right)-\nabla f\left(x_{n}+e_{n}\right)\right\| .
\end{aligned}
$$

Therefore,

$$
\begin{aligned}
&\left(1-\alpha_{n}\right) \beta_{n}\left\|\nabla f\left(x_{n+1}\right)-\nabla f\left(T\left(x_{n}+e_{n}\right)\right)\right\| \\
& \leq\left\|\nabla f\left(x_{n+1}\right)-\nabla f\left(y_{n}\right)\right\|+\alpha_{n}\left\|\nabla f\left(x_{n+1}\right)-\nabla f\left(x_{n}+e_{n}\right)\right\| \\
&+\left(1-\alpha_{n}\right)\left(1-\beta_{n}\right)\left\|\nabla f\left(x_{n+1}\right)-\nabla f\left(x_{n}+e_{n}\right)\right\| .
\end{aligned}
$$

In view of $\liminf _{n \rightarrow \infty}\left(1-\alpha_{n}\right) \beta_{n}>0$ and from both (3.16) and (3.19), one has

$$
\lim _{n \rightarrow \infty}\left\|\nabla f\left(x_{n+1}\right)-\nabla f\left(T\left(x_{n}+e_{n}\right)\right)\right\|=0 .
$$

Furthermore, we have

$$
\lim _{n \rightarrow \infty}\left\|x_{n+1}-T\left(x_{n}+e_{n}\right)\right\|=0,
$$

and so, by (3.14),

$$
\lim _{n \rightarrow \infty}\left\|\left(x_{n}+e_{n}\right)-T\left(x_{n}+e_{n}\right)\right\|=0 .
$$

Since $x_{n} \rightarrow \bar{\omega}$ and $e_{n} \rightarrow 0$, we get $\bar{\omega} \in \tilde{F}(T)=F(T)$.

Finally, we show $\bar{\omega}=\operatorname{proj}_{F(T)}^{f}\left(x_{0}\right)$. Since $\operatorname{proj}_{F(T)}^{f}\left(x_{0}\right) \in F(T) \subset C_{n} \cap Q_{n}$, it follows from $x_{n+1}=\operatorname{proj}_{\left(C_{n} \cap Q_{n}\right)}^{f}\left(x_{0}\right)$ that $D_{f}\left(x_{n+1}, x_{0}\right) \leq D_{f}\left(\operatorname{proj}_{F(T)}^{f}\left(x_{0}\right), x_{0}\right)$. By Lemma 2.15, $x_{n} \rightarrow$ $\operatorname{proj}_{F(T)}^{f}\left(x_{0}\right)$ as $n \rightarrow \infty$. Therefore, $\left\{x_{n}\right\}$ and $\left\{y_{n}\right\}$ converge strongly to $\operatorname{proj}_{F(T)}^{f}\left(x_{0}\right)$. This completes the proof. 
Theorem 3.2. Let $C$ be a nonempty closed convex subset of a real reflexive Banach space $E$ and $f$ : $E \rightarrow R$ a Legendre function which is bounded, uniformly Fréchet differentiable, and totally convex on bounded subset of $E$, and let $T: C \rightarrow C$ be a Bregman relatively nonexpansive mapping such that $F(T) \neq \emptyset$. Assume that $\left\{\alpha_{n}\right\},\left\{\beta_{n}\right\} \subset[0,1]$ such that $\liminf _{n \rightarrow \infty}\left(1-\alpha_{n}\right) \beta_{n}>0$, and $\left\{e_{n}\right\}$ is an error sequence in $E$ with $e_{n} \rightarrow 0$ as $n \rightarrow \infty$. Then, the sequences $\left\{x_{n}\right\}$ and $\left\{y_{n}\right\}$ generated by (3.1) converge strongly to the point $\operatorname{proj}_{F(T)}^{f}\left(x_{0}\right)$, where $\operatorname{proj}_{F(T)}^{f}\left(x_{0}\right)$ is the Bregman projection of $C$ onto $F(T)$.

Proof. As in the proof of Theorem 3.1, we know that the sequences $\left\{x_{n}\right\}$ and $\left\{y_{n}\right\}$ converge strongly to $\bar{\omega} \in C$, and so,

$$
\lim _{n \rightarrow \infty}\left\|\left(x_{n}+e_{n}\right)-T\left(x_{n}+e_{n}\right)\right\|=0 .
$$

Then, for any subsequence $\left\{x_{n k}\right\}$ of $\left\{x_{n}\right\}$ converges weakly to $\bar{\omega}$,

$$
\lim _{k \rightarrow \infty}\left\|\left(x_{n k}+e_{n k}\right)-T\left(x_{n k}+e_{n k}\right)\right\|=0 .
$$

Therefore, $\bar{\omega} \in \widehat{F}(T)=F(T)$. By the similar proof of Theorem 3.2, the sequences $\left\{x_{n}\right\}$ and $\left\{y_{n}\right\}$ converge strongly to $\operatorname{proj}_{F(T)}^{f}\left(x_{0}\right)$. This completes the proof.

If $\alpha_{n} \equiv 0, e_{n} \equiv 0$, and $f(x)=(1 / 2)\|x\|^{2}$ for all $x \in E, n \geq 0$, then from Remark 2.4 and Theorem 3.1, we have the following result.

Corollary 3.3. Let $C$ be a nonempty closed convex subset of a real reflexive, smooth, and strictly convex Banach space $E$, and let $T: C \rightarrow C$ be a relatively nonexpansive mapping such that $F(T) \neq \emptyset$. Define a sequence $\left\{x_{n}\right\}$ in $C$ by the following algorithm:

$$
\begin{gathered}
x_{0} \in C, \quad Q_{0}=C, \\
y_{n}=J^{-1}\left(\beta_{n} J\left(T\left(x_{n}\right)\right)+\left(1-\beta_{n}\right) J\left(x_{n}\right)\right), \\
C_{n}=\left\{z \in C_{n-1} \cap Q_{n-1}: \phi\left(z, y_{n}\right) \leq \phi\left(z, x_{n}\right)\right\}, \\
C_{0}=\left\{z \in C: \phi\left(z, y_{0}\right) \leq \phi\left(z, x_{0}\right)\right\}, \\
Q_{n}=\left\{z \in C_{n-1} \cap Q_{n-1}:\left\langle J\left(x_{0}\right)-J\left(x_{n}\right), z-x_{n}\right\rangle \leq 0\right\}, \\
x_{n+1}=\prod_{C_{n} \cap Q_{n}} x_{0}, \quad \forall n \geq 0,
\end{gathered}
$$

where $J$ is the duality mapping on $E,\left\{\beta_{n}\right\} \subset[0,1]$ such that $\lim _{n \rightarrow \infty} \inf _{n \rightarrow \infty}>0$. Then, the sequences $\left\{x_{n}\right\}$ and $\left\{y_{n}\right\}$ converge strongly to the point $\Pi_{F(T)}\left(x_{0}\right)$, where $\Pi_{F(T)}\left(x_{0}\right)$ is the generalized projection (see, e.g., $[2,3,28]$ ) of $C$ onto $F(T)$.

In [27], Matsushita and Takahashi proved the following result.

Theorem MT (see [27, Theorem 3.1]). Let C be a nonempty closed convex subset of a real uniformly convex and uniformly smooth Banach space $E$, and let $T: C \rightarrow C$ be a relatively nonexpansive mapping such that $F(T) \neq \emptyset$. Assume that $\left\{\alpha_{n}\right\}$ is a sequence of real numbers such that $0 \leq \alpha_{n}<1$ 
and $\lim \sup _{n \rightarrow \infty} \alpha_{n}<1$. Then, the sequence $\left\{x_{n}\right\}$ generated by (1.3) converges strongly to the point $\Pi_{F(T)}\left(x_{0}\right)$, where $\Pi_{F(T)}\left(x_{0}\right)$ is the generalized projection (see, e.g., $\left.[2,3,28]\right)$ of $C$ onto $F(T)$.

Remark 3.4. Corollary 3.3 extends Theorem MT [27] from uniformly convex and uniformly smooth Banach spaces to reflexive, smooth, and strictly convex Banach space.

Now, we investigate convergence theorems for Halpern-type iterative algorithms with errors.

Theorem 3.5. Let $C$ be a nonempty closed convex subset of a real reflexive Banach space $E$ and $f$ : $E \rightarrow R$ a Legendre function which is bounded, uniformly Fréchet differentiable, and totally convex on bounded subset of $E$, and let $T: C \rightarrow C$ be a weak Bregman relatively nonexpansive mapping such that $F(T) \neq \emptyset$. Define a sequence $\left\{x_{n}\right\}$ in $C$ by the following algorithm:

$$
\begin{gathered}
x_{0} \in C, \quad Q_{0}=C, \\
z_{n}=\nabla f^{*}\left(\beta_{n} \nabla f\left(x_{0}\right)+\left(1-\beta_{n}\right) \nabla f\left(T\left(x_{n}+e_{n}\right)\right)\right), \\
y_{n}=\nabla f^{*}\left(\alpha_{n} \nabla f\left(z_{n}\right)+\left(1-\alpha_{n}\right) \nabla f\left(x_{n}+e_{n}\right)\right), \\
C_{n}=\left\{z \in C_{n-1} \cap Q_{n-1}: D_{f}\left(z, y_{n}\right) \leq\left(1-\alpha_{n} \beta_{n}\right) D_{f}\left(z, x_{n}+e_{n}\right)+\alpha_{n} \beta_{n} D_{f}\left(z, x_{0}\right)\right\}, \\
C_{0}=\left\{z \in C: D_{f}\left(z, y_{0}\right) \leq D_{f}\left(z, x_{0}\right)\right\}, \\
Q_{n}=\left\{z \in C_{n-1} \cap Q_{n-1}:\left\langle\nabla f\left(x_{0}\right)-\nabla f\left(x_{n}\right), z-x_{n}\right\rangle \leq 0\right\}, \\
x_{n+1}=\operatorname{proj}_{\left(C_{n} \cap Q_{n}\right)}^{f} x_{0}, \quad \forall n \geq 0,
\end{gathered}
$$

where $\left\{\alpha_{n}\right\},\left\{\beta_{n}\right\} \subset[0,1]$ such that $\liminf _{n \rightarrow \infty} \alpha_{n}>0$ and $\lim _{n \rightarrow \infty} \beta_{n}=0$, and $\left\{e_{n}\right\}$ is an error sequence in $E$ with $e_{n} \rightarrow 0$ as $n \rightarrow \infty$. Then, the sequences $\left\{x_{n}\right\}$ and $\left\{y_{n}\right\}$ converge strongly to the point $\operatorname{proj}_{F(T)}^{f}\left(x_{0}\right)$, where $\operatorname{proj}_{F(T)}^{f}\left(x_{0}\right)$ is the Bregman projection of $C$ onto $F(T)$.

Proof. By Proposition 2.17, it follows that $F(T)$ is a nonempty closed and convex subset of $E$. It is easy to see that $C_{n}$ is closed and $Q_{n}$ is closed and convex for all $n \geq 0$. For any $z \in C_{n}$, $n \geq 1$,

$$
\begin{aligned}
D_{f}\left(z, y_{n}\right) \leq\left(1-\alpha_{n} \beta_{n}\right) D_{f}\left(z, x_{n}+e_{n}\right)+\alpha_{n} \beta_{n} D_{f}\left(z, x_{0}\right) \\
\Longleftrightarrow f(z)-f\left(y_{n}\right)-\left\langle\nabla f\left(y_{n}\right), z-y_{n}\right\rangle \\
\quad \leq\left(1-\alpha_{n} \beta_{n}\right)\left(f(z)-f\left(x_{n}+e_{n}\right)-\left\langle\nabla f\left(x_{n}+e_{n}\right), z-x_{n}-e_{n}\right\rangle\right) \\
\quad+\alpha_{n} \beta_{n}\left(f(z)-f\left(x_{0}\right)-\left\langle\nabla f\left(x_{0}\right), z-x_{0}\right\rangle\right) \\
\Longleftrightarrow\left(1-\alpha_{n} \beta_{n}\right) f\left(x_{n}+e_{n}\right)+\alpha_{n} \beta_{n} f\left(x_{0}\right)-f\left(y_{n}\right) \\
\quad \leq\left\langle\nabla f\left(y_{n}\right), z-y_{n}\right\rangle-\left(1-\alpha_{n} \beta_{n}\right)\left\langle\nabla f\left(x_{n}+e_{n}\right), z-x_{n}-e_{n}\right\rangle-\alpha_{n} \beta_{n}\left\langle\nabla f\left(x_{0}\right), z-x_{0}\right\rangle,
\end{aligned}
$$


which implies that $C_{n}$ is closed and convex for all $n \geq 1$. Since, for any $z \in C_{0}$,

$$
\begin{aligned}
& D_{f}\left(z, y_{0}\right) \leq D_{f}\left(z, x_{0}\right) \\
& \Longleftrightarrow f(z)-f\left(y_{0}\right)-\left\langle\nabla f\left(y_{0}\right), z-y_{0}\right\rangle \leq f(z)-f\left(x_{0}\right)-\left\langle\nabla f\left(x_{0}\right), z-x_{0}\right\rangle \\
& \Longleftrightarrow\left\langle\nabla f\left(x_{0}\right), z-x_{0}\right\rangle-\left\langle\nabla f\left(y_{0}\right), z-y_{0}\right\rangle \leq f\left(y_{0}\right)-f\left(x_{0}\right) \\
& \Longleftrightarrow\left\langle\nabla f\left(x_{0}\right), z-x_{0}\right\rangle-\left\langle\nabla f\left(y_{0}\right), z-x_{0}+x_{0}-y_{0}\right\rangle \leq f\left(y_{0}\right)-f\left(x_{0}\right) \\
& \Longleftrightarrow\left\langle\nabla f\left(x_{0}\right)-\nabla f\left(y_{0}\right), z-x_{0}\right\rangle+D_{f}\left(x_{0}, y_{0}\right) \leq 0,
\end{aligned}
$$

which shows that $C_{0}$ is closed and convex. As a consequence, $C_{n}$ is closed and convex for all $n \geq 0$. Taking $p \in F(T)$ arbitrarily, by Lemma 2.18,

$$
\begin{aligned}
D_{f}\left(p, y_{n}\right) & =D_{f}\left(p, \nabla f^{*}\left(\alpha_{n} \nabla f\left(z_{n}\right)+\left(1-\alpha_{n}\right) \nabla f\left(x_{n}+e_{n}\right)\right)\right) \\
& \leq \alpha_{n} D_{f}\left(p, z_{n}\right)+\left(1-\alpha_{n}\right) D_{f}\left(p, x_{n}+e_{n}\right) \\
& =\left(1-\alpha_{n}\right) D_{f}\left(p, x_{n}+e_{n}\right)+\alpha_{n} D_{f}\left(p, \nabla f^{*}\left(\beta_{n} \nabla f\left(x_{0}\right)+\left(1-\beta_{n}\right) \nabla f\left(T\left(x_{n}+e_{n}\right)\right)\right)\right) \\
& \leq\left(1-\alpha_{n}\right) D_{f}\left(p, x_{n}+e_{n}\right)+\alpha_{n} \beta_{n} D_{f}\left(p, x_{0}\right)+\alpha_{n}\left(1-\beta_{n}\right) D_{f}\left(p, T\left(x_{n}+e_{n}\right)\right) \\
& \leq\left(1-\alpha_{n}\right) D_{f}\left(p, x_{n}+e_{n}\right)+\alpha_{n} \beta_{n} D_{f}\left(p, x_{0}\right)+\alpha_{n}\left(1-\beta_{n}\right) D_{f}\left(p, x_{n}+e_{n}\right) \\
& =\left(1-\alpha_{n} \beta_{n}\right) D_{f}\left(p, x_{n}+e_{n}\right)+\alpha_{n} \beta_{n} D_{f}\left(p, x_{0}\right),
\end{aligned}
$$

that is, $p \in C_{n}$, and so, $F(T) \subset C_{n}$ for all $n \geq 0$. As in the proof of Theorem 3.1, we get $F(T) \subset Q_{n}$ for all $n \geq 0,\left\{x_{n}\right\}$ is a Cauchy sequence, $\left\{x_{n}\right\},\left\{y_{n}\right\}$, and $\left\{z_{n}\right\}$ are also bounded, and thus,

$$
\begin{gathered}
\lim _{n \rightarrow \infty} D_{f}\left(x_{n+1}, x_{n}+e_{n}\right)=0, \quad \lim _{n \rightarrow \infty}\left\|\left(x_{n+1}+e_{n+1}\right)-\left(x_{n}+e_{n}\right)\right\|=0, \\
\lim _{n \rightarrow \infty}\left\|x_{n+1}-\left(x_{n}+e_{n}\right)\right\|=0 .
\end{gathered}
$$

Consequently, $F(T) \subset C_{n} \cap Q_{n}$ and $C_{n} \cap Q_{n}$ is nonempty closed and convex for all $n \geq 0$. Moreover, $\left\{x_{n}\right\}$ is well defined. Set $x_{n} \rightarrow \bar{\omega} \in C$.

Secondly, we show that $\left\{x_{n}\right\}$ converges strongly to a point of $F(T)$. Since $f$ is uniformly Fréchet differentiable on bounded subsets of $E$, from Lemma 2.12, $\nabla f$ is norm-to-norm uniformly continuous on bounded subsets of $E$. So, by (3.33),

$$
\lim _{n \rightarrow \infty}\left\|\nabla f\left(x_{n+1}\right)-\nabla f\left(x_{n}+e_{n}\right)\right\|=0 .
$$

In view of $x_{n+1}=\operatorname{proj}_{\left(C_{n} \cap Q_{n}\right)}^{f}\left(x_{0}\right) \in C_{n}$, we have

$$
D_{f}\left(x_{n+1}, y_{n}\right) \leq\left(1-\alpha_{n} \beta_{n}\right) D_{f}\left(x_{n+1}, x_{n}+e_{n}\right)+\alpha_{n} \beta_{n} D_{f}\left(x_{n+1}, x_{0}\right)
$$


International Journal of Mathematics and Mathematical Sciences

Due to $\lim _{n \rightarrow \infty} \beta_{n}=0$, from (3.32), one has

$$
\lim _{n \rightarrow \infty} D_{f}\left(x_{n+1}, y_{n}\right)=0
$$

Therefore, $\lim _{n \rightarrow \infty}\left\|x_{n+1}-y_{n}\right\|=0$. Moreover, one has

$$
\lim _{n \rightarrow \infty}\left\|\nabla f\left(x_{n+1}\right)-\nabla f\left(y_{n}\right)\right\|=0
$$

Since $\left\|x_{n}-y_{n}\right\| \leq\left\|x_{n}-x_{n+1}\right\|+\left\|x_{n+1}-y_{n}\right\|$, by (3.32) and (3.33),

$$
\lim _{n \rightarrow \infty}\left\|x_{n}-y_{n}\right\|=0,
$$

and thus, $y_{n} \rightarrow \bar{\omega}$ as $n \rightarrow \infty$. Noticing that

$$
\begin{aligned}
&\left\|\nabla f\left(x_{n+1}\right)-\nabla f\left(y_{n}\right)\right\| \\
&=\left\|\nabla f\left(x_{n+1}\right)-\left(\alpha_{n} \nabla f\left(z_{n}\right)+\left(1-\alpha_{n}\right) \nabla f\left(x_{n}+e_{n}\right)\right)\right\| \\
& \geq \alpha_{n}\left\|\nabla f\left(x_{n+1}\right)-\nabla f\left(z_{n}\right)\right\|-\left(1-\alpha_{n}\right)\left\|\nabla f\left(x_{n+1}\right)-\nabla f\left(x_{n}+e_{n}\right)\right\| \\
&= \alpha_{n}\left\|\nabla f\left(x_{n+1}\right)-\left(\beta_{n} \nabla f\left(x_{0}\right)+\left(1-\beta_{n}\right) \nabla f\left(T_{n}\left(x_{n}+e_{n}\right)\right)\right)\right\| \\
&-\left(1-\alpha_{n}\right)\left\|\nabla f\left(x_{n+1}\right)-\nabla f\left(x_{n}+e_{n}\right)\right\| \\
& \geq \alpha_{n}\left(1-\beta_{n}\right)\left\|\nabla f\left(x_{n+1}\right)-\nabla f\left(T_{n}\left(x_{n}+e_{n}\right)\right)\right\|-\alpha_{n} \beta_{n}\left\|\nabla f\left(x_{n+1}\right)-\nabla f\left(x_{0}\right)\right\| \\
&-\left(1-\alpha_{n}\right)\left\|\nabla f\left(x_{n+1}\right)-\nabla f\left(x_{n}+e_{n}\right)\right\| .
\end{aligned}
$$

That is,

$$
\begin{aligned}
& \alpha_{n}\left(1-\beta_{n}\right)\left\|\nabla f\left(x_{n+1}\right)-\nabla f\left(T\left(x_{n}+e_{n}\right)\right)\right\| \\
& \leq\left\|\nabla f\left(x_{n+1}\right)-\nabla f\left(y_{n}\right)\right\|+\alpha_{n} \beta_{n}\left\|\nabla f\left(x_{n+1}\right)-\nabla f\left(x_{0}\right)\right\| \\
&+\left(1-\alpha_{n}\right)\left\|\nabla f\left(x_{n+1}\right)-\nabla f\left(x_{n}+e_{n}\right)\right\| .
\end{aligned}
$$

Together with $\liminf _{n \rightarrow \infty} \alpha_{n}>0, \lim _{n \rightarrow \infty} \beta_{n}=0$, and (3.37), this yields that

$$
\lim _{n \rightarrow \infty}\left\|\nabla f\left(x_{n+1}\right)-\nabla f\left(T\left(x_{n}+e_{n}\right)\right)\right\|=0 .
$$

Since $f$ is uniformly Fréchet differentiable on bounded subsets of $E$, from Lemma 2.12, $\nabla f$ is norm-to-norm uniformly continuous on bounded subsets of $E$ and so is $\nabla f^{*}$. Then, by (3.41), we get

$$
\lim _{n \rightarrow \infty}\left\|x_{n+1}-T\left(x_{n}+e_{n}\right)\right\|=0 .
$$


From $\left\|\left(x_{n}+e_{n}\right)-T\left(x_{n}+e_{n}\right)\right\| \leq\left\|\left(x_{n}+e_{n}\right)-\left(x_{n+1}+e_{n+1}\right)\right\|+\left\|\left(x_{n+1}+e_{n+1}\right)-T\left(x_{n}+e_{n}\right)\right\|$, it follows that $\lim _{n \rightarrow \infty}\left\|\left(x_{n}+e_{n}\right)-T\left(x_{n+1}+e_{n+1}\right)\right\|=0$. So, $\bar{\omega} \in \widetilde{F}(T)=F(T)$. By the same argument of Theorem 3.1, we know that $\left\{x_{n}\right\}$ and $\left\{y_{n}\right\}$ converge strongly to $\operatorname{proj}_{F(T)}^{f}\left(x_{0}\right)$. This completes the proof.

If $\alpha_{n} \equiv 1$ and $e_{n} \equiv 0$ for all $n \geq 0$, then from Theorem 3.5, we have the following result.

Corollary 3.6. Let $C$ be a nonempty closed convex subset of a real reflexive Banach space $E$ and $f$ : $E \rightarrow R$ a Legendre function which is bounded, uniformly Fréchet differentiable, and totally convex on bounded subset of $E$, and let $T$ be a weak Bregman relatively nonexpansive mapping from $C$ into itself such that $F(T) \neq \emptyset$. Define a sequence $\left\{x_{n}\right\}$ in $C$ by the following algorithm:

$$
\begin{gathered}
x_{0} \in C, \quad Q_{0}=C, \\
y_{n}=\nabla f^{*}\left(\beta_{n} \nabla f\left(x_{0}\right)+\left(1-\beta_{n}\right) \nabla f\left(T x_{n}\right)\right), \\
C_{n}=\left\{z \in C_{n-1} \cap Q_{n-1}: D_{f}\left(z, y_{n}\right) \leq\left(1-\beta_{n}\right) D_{f}\left(z, x_{n}\right)+\beta_{n} D_{f}\left(z, x_{0}\right)\right\}, \\
C_{0}=\left\{z \in C: D_{f}\left(z, y_{0}\right) \leq D_{f}\left(z, x_{0}\right)\right\}, \\
Q_{n}=\left\{z \in C_{n-1} \cap Q_{n-1}:\left\langle\nabla f\left(x_{0}\right)-\nabla f\left(x_{n}\right), z-x_{n}\right\rangle \leq 0\right\}, \\
x_{n+1}=\operatorname{proj}_{C_{n} \cap Q_{n}}^{f} x_{0}, \quad \forall n \geq 0,
\end{gathered}
$$

where $\left\{\beta_{n}\right\} \subset[0,1]$ such that $\lim _{n \rightarrow \infty} \beta_{n}=0$ and $\left\{e_{n}\right\}$ is an error sequence in $E$ with $e_{n} \rightarrow 0$ as $n \rightarrow \infty$. Then, the sequences $\left\{x_{n}\right\}$ and $\left\{y_{n}\right\}$ converges strongly to the point $\operatorname{proj}_{F(T)}^{f}\left(x_{0}\right)$, where $\operatorname{proj}_{F(T)}^{f}\left(x_{0}\right)$ is the Bregman projection of $C$ onto $F(T)$.

Now, we develop a strong convergence theorem for a Bregman relatively nonexpansive mapping.

Theorem 3.7. Let $C$ be a nonempty closed convex subset of a real reflexive Banach space $E$ and $f$ : $E \rightarrow R$ a Legendre function which is bounded, uniformly Fréchet differentiable, and totally convex on bounded subset of $E$, and let $T: C \rightarrow C$ be a Bregman relatively nonexpansive mapping such that $F(T) \neq \emptyset$. Define a sequence $\left\{x_{n}\right\}$ in $C$ by the following algorithm:

$$
\begin{gathered}
x_{0} \in C, \quad Q_{0}=C, \\
z_{n}=\nabla f^{*}\left(\beta_{n} \nabla f\left(x_{0}\right)+\left(1-\beta_{n}\right) \nabla f\left(T\left(x_{n}+e_{n}\right)\right)\right), \\
y_{n}=\nabla f^{*}\left(\alpha_{n} \nabla f\left(z_{n}\right)+\left(1-\alpha_{n}\right) \nabla f\left(x_{n}+e_{n}\right)\right), \\
C_{n}=\left\{z \in C_{n-1} \cap Q_{n-1}: D_{f}\left(z, y_{n}\right) \leq\left(1-\alpha_{n} \beta_{n}\right) D_{f}\left(z, x_{n}+e_{n}\right)+\alpha_{n} \beta_{n} D_{f}\left(z, x_{0}\right)\right\}, \\
C_{0}=\left\{z \in C: D_{f}\left(z, y_{0}\right) \leq D_{f}\left(z, x_{0}\right)\right\}, \\
Q_{n}=\left\{z \in C_{n-1} \cap Q_{n-1}:\left\langle\nabla f\left(x_{0}\right)-\nabla f\left(x_{n}\right), z-x_{n}\right\rangle \leq 0\right\}, \\
x_{n+1}=\operatorname{proj}_{C_{n} \cap Q_{n}}^{f} x_{0}, \quad \forall n \geq 0,
\end{gathered}
$$


where $\left\{\alpha_{n}\right\},\left\{\beta_{n}\right\} \subset[0,1]$ such that $\liminf _{n \rightarrow \infty} \alpha_{n}>0$ and $\lim _{n \rightarrow \infty} \beta_{n}=0$ and $\left\{e_{n}\right\}$ is an error sequence in $E$ with $e_{n} \rightarrow 0$ as $n \rightarrow \infty$. Then, the sequences $\left\{x_{n}\right\}$ and $\left\{y_{n}\right\}$ converges strongly to the point $\operatorname{proj}_{F(T)}^{f}\left(x_{0}\right)$, where $\operatorname{proj}_{F(T)}^{f}\left(x_{0}\right)$ is the Bregman projection of $C$ onto $F(T)$.

Proof. The proof is similar to Theorem 3.5 and so is omitted. This completes the proof.

$$
\text { If } \alpha_{n} \equiv 1 \text { and } e_{n} \equiv 0 \text { for all } n \geq 0 \text {, then from Theorem 3.7, we get the following corollary. }
$$

Corollary 3.8. Let $E$ be a real reflexive Banach space and $f: E \rightarrow R$ a Legendre function which is bounded, uniformly Fréchet differentiable, and totally convex on bounded subset of $E$, and let $T$ : $E \rightarrow E$ be a Bregman relatively nonexpansive mapping such that $F(T) \neq \emptyset$. Assume that $\left\{\beta_{n}\right\}$ is a real sequence in $[0,1]$ such that $\lim _{n \rightarrow \infty} \beta_{n}=0$. Define a sequence $\left\{x_{n}\right\}$ by the following algorithm:

$$
\begin{gathered}
x_{0} \in C, \quad Q_{0}=C, \\
y_{n}=\nabla f^{*}\left(\beta_{n} \nabla f\left(x_{0}\right)+\left(1-\beta_{n}\right) \nabla f\left(T x_{n}\right)\right), \\
C_{n}=\left\{z \in C_{n-1} \cap Q_{n-1}: D_{f}\left(z, y_{n}\right) \leq\left(1-\alpha_{n} \beta_{n}\right) D_{f}\left(z, x_{n}\right)+\alpha_{n} \beta_{n} D_{f}\left(z, x_{0}\right)\right\}, \\
C_{0}=\left\{z \in C: D_{f}\left(z, y_{0}\right) \leq D_{f}\left(z, x_{0}\right)\right\}, \\
Q_{n}=\left\{z \in C_{n-1} \cap Q_{n-1}:\left\langle\nabla f\left(x_{0}\right)-\nabla f\left(x_{n}\right), z-x_{n}\right\rangle \leq 0\right\}, \\
x_{n+1}=\operatorname{proj}_{C_{n} \cap Q_{n}}^{f} x_{0}, \quad \forall n \geq 0 .
\end{gathered}
$$

Then, the sequences $\left\{x_{n}\right\}$ and $\left\{y_{n}\right\}$ converge strongly to the point $\operatorname{proj}_{F(T)}^{f}\left(x_{0}\right)$, where $\operatorname{proj}_{F(T)}^{f}\left(x_{0}\right)$ is the Bregman projection of $C$ onto $F(T)$.

In [30], Qin and Su obtained the following.

Theorem QS (see [30, Theorem 2.2]). Let $C$ be a nonempty closed convex subset of a uniformly convex and uniformly smooth Banach space $E$, and let $T: C \rightarrow C$ be a relatively nonexpansive mapping such that $F(T) \neq \emptyset$. Assume that $\left\{\beta_{n}\right\}$ is a real sequence in $[0,1)$ such that $\lim _{n \rightarrow \infty} \beta_{n}=0$. Then, the sequence $\left\{x_{n}\right\}$ generated by (1.5) converges strongly to $\Pi_{F(T)} x_{0}$, where $\Pi_{F(T)}$ is the generalized projection (see, e.g., [2, 3]) from $E$ onto $F(T)$.

Remark 3.9. Corollary 3.8 extends Theorems QS [30] from uniformly convex and uniformly smooth Banach spaces to reflexive Banach spaces.

\section{Conclusions}

In this paper, we introduce a conception of weak Bregman relatively nonexpansive mapping in reflexive Banach space and give an example to illustrate the existence of weak Bregman relatively nonexpansive mapping and the difference between weak Bregman relatively nonexpansive mapping and Bregman relatively nonexpansive mapping which enlarge the Bregman operator theory. Secondly, by using projection techniques, we construct several modification of Mann-type iterative algorithms with errors and Halpern-type iterative algorithms with errors to find fixed points of weak Bregman relatively nonexpansive mappings and Bregman relatively nonexpansive mappings in Banach spaces. Thirdly, strong convergence 
theorems for weak Bregman relatively nonexpansive mappings and Bregman relatively nonexpansive mappings are derived under some suitable assumptions. By further research, on the one hand, we may apply our algorithms to find zeros of finite families of maximal monotone operators, solutions of system of convex minization problems, solutions of system of variational inequalities, equilibrium, and equation operators (see, e.g., [24]). On the other hand, one may give some numerical experiments to verify the theoretical assertions and show how to compute the generalized projections. These topics will be done in the future.

\section{Acknowledgments}

The authors would like to thank anonymous referees for their constructive review and useful comments on an earlier version of the work and express gratitude to Professor Simenon Reich, Department of Mathematics, The Technion-Israel Institute of Technology, Israel, and Professor Yeol Je Cho, Department of Mathematics Education and the RINS, Gyeongsang National University, Chinju 660-701, Korea, for providing their nice works. This research is supported by the Natural Science Foundation of China (nos. 70771080, 60804065) and the Fundamental Research Fund for the Central Universities (201120102020004).

\section{References}

[1] L. M. Brègman, "A relaxation method of finding a common point of convex sets and its application to the solution of problems in convex programming," USSR Computational Mathematics and Mathematical Physics, vol. 7, no. 3, pp. 200-217, 1967.

[2] Ya. I. Alber, "Generalized projection operators in Banach spaces: properties and applications," in Functional-Differential Equations, vol. 1 of Proceedings of the Israel Seminar Ariel, Israel, Function Differential Equation, pp. 1-21, The College of Judea and Samaria, Ariel, Israel, 1994.

[3] Y. I. Alber, "Metric and generalized projection operators in Banach spaces: properties and applications," in Theory and Applications of Nonlinear Operators of Accretive and Monotone Type, vol. 178 of Lecture Notes in Pure and Applied Mathematics, pp. 15-50, Dekker, New York, NY, USA, 1996.

[4] Y. Alber and D. Butnariu, "Convergence of Bregman projection methods for solving consistent convex feasibility problems in reflexive Banach spaces," Journal of Optimization Theory and Applications, vol. 92, no. 1, pp. 33-61, 1997.

[5] H. H. Bauschke and J. M. Borwein, "Legendre functions and the method of random Bregman projections," Journal of Convex Analysis, vol. 4, no. 1, pp. 27-67, 1997.

[6] H. H. Bauschke and A. S. Lewis, "Dykstra's algorithm with Bregman projections: a convergence proof," Optimization, vol. 48, no. 4, pp. 409-427, 2000.

[7] H. H. Bauschke, J. M. Borwein, and P. L. Combettes, "Essential smoothness, essential strict convexity, and Legendre functions in Banach spaces," Communications in Contemporary Mathematics, vol. 3, no. 4, pp. 615-647, 2001.

[8] H. H. Bauschke, J. M. Borwein, and P. L. Combettes, "Bregman monotone optimization algorithms," SIAM Journal on Control and Optimization, vol. 42, no. 2, pp. 596-636, 2003.

[9] H. H. Bauschke and P. L. Combettes, "Construction of best Bregman approximations in reflexive Banach spaces," Proceedings of the American Mathematical Society, vol. 131, no. 12, pp. 3757-3766, 2003.

[10] R. S. Burachik, Generalized proximal point methods for the variational inequality problem, Ph.D. thesis, Instituto de Mathematica Pura e Aplicada (IMPA), Rio de Janeiro, Brazil, 1995.

[11] R. S. Burachik and S. Scheimberg, "A proximal point method for the variational inequality problem in Banach spaces," SIAM Journal on Control and Optimization, vol. 39, no. 5, pp. 1633-1649, 2000.

[12] D. Butnariu and A. N. Iusem, Totally Convex Functions for Fixed Points Computation and Infinite Dimensional Optimization, vol. 40 of Applied Optimization, Kluwer Academic Publishers, Dordrecht, The Netherlands, 2000.

[13] D. Butnariu, A. N. Iusem, and C. Zălinescu, “On uniform convexity, total convexity and convergence of the proximal point and outer Bregman projection algorithms in Banach spaces," Journal of Convex Analysis, vol. 10, no. 1, pp. 35-61, 2003. 
[14] D. Butnariu and E. Resmerita, "Bregman distances, totally convex functions, and a method for solving operator equations in Banach spaces," Abstract and Applied Analysis, vol. 2006, Article ID 84919, 39 pages, 2006.

[15] J. W. Chen, Y. J. Cho, J. K. Kim, and J. Li, "Multiobjective optimization problems with modified objective functions and cone constraints and applications," Journal of Global Optimization, vol. 49, no. 1, pp. 137-147, 2011.

[16] J. Eckstein, "Nonlinear proximal point algorithms using Bregman functions, with applications to convex programming," Mathematics of Operations Research, vol. 18, no. 1, pp. 202-226, 1993.

[17] K. C. Kiwiel, "Proximal minimization methods with generalized Bregman functions," SIAM Journal on Control and Optimization, vol. 35, no. 4, pp. 1142-1168, 1997.

[18] S. Reich, "A weak convergence theorem for the alternating method with Bregman distances," in Theory and Applications of Nonlinear Operators of Accretive and Monotone Type, vol. 178 of Lecture Notes in Pure and Applied Mathematics, pp. 313-318, Dekker, New York, NY, USA, 1996.

[19] E. Resmerita, "On total convexity, Bregman projections and stability in Banach spaces," Journal of Convex Analysis, vol. 11, no. 1, pp. 1-16, 2004.

[20] S. Reich and S. Sabach, "A strong convergence theorem for a proximal-type algorithm in reflexive Banach spaces," Journal of Nonlinear and Convex Analysis, vol. 10, no. 3, pp. 471-485, 2009.

[21] S. Reich and S. Sabach, "Two strong convergence theorems for a proximal method in reflexive Banach spaces," Numerical Functional Analysis and Optimization, vol. 31, no. 1-3, pp. 22-44, 2010.

[22] S. Reich and S. Sabach, "Two strong convergence theorems for Bregman strongly nonexpansive operators in reflexive Banach spaces," Nonlinear Analysis: Theory, Methods E Applications, vol. 73, no. 1, pp. 122-135, 2010.

[23] S. Reich and S. Sabach, "Existence and approximation of fixed points of Bregman firmly nonexpansive mappings in reflexive Banach spaces," in Fixed-Point Algorithms for Inverse Problems in Science and Engineering, Springer, New York, NY, USA, 2011.

[24] S. Reich and S. Sabach, "A projection method for solving nonlinear problems in reflexive Banach spaces," Journal of Fixed Point Theory and Applications. In press.

[25] M. V. Solodov and B. F. Svaiter, "An inexact hybrid generalized proximal point algorithm and some new results on the theory of Bregman functions," Mathematics of Operations Research, vol. 25, no. 2, pp. 214-230, 2000.

[26] K. Nakajo and W. Takahashi, "Strong convergence theorems for nonexpansive mappings and nonexpansive semigroups," Journal of Mathematical Analysis and Applications, vol. 279, no. 2, pp. 372-379, 2003.

[27] S. Matsushita and W. Takahashi, "A strong convergence theorem for relatively nonexpansive mappings in a Banach space," Journal of Approximation Theory, vol. 134, no. 2, pp. 257-266, 2005.

[28] J. W. Chen and Y. Z. Zou, "Existence of solutions of F-implicit variational inequality problems with extended projection operators," Acta Mathematica Sinica. Chinese Series, vol. 53, no. 2, pp. 375-384, 2010.

[29] C. Martinez-Yanes and H.-K. Xu, "Strong convergence of the CQ method for fixed point iteration processes," Nonlinear Analysis: Theory, Methods E Applications, vol. 64, no. 11, pp. 2400-2411, 2006.

[30] X. Qin and Y. Su, "Strong convergence theorems for relatively nonexpansive mappings in a Banach space," Nonlinear Analysis: Theory, Methods E Applications, vol. 67, no. 6, pp. 1958-1965, 2007.

[31] J. F. Bonnans and A. Shapiro, Perturbation Analysis of Optimization Problems, Springer Series in Operations Research, Springer, New York, NY, USA, 2000.

[32] S. Plubtieng and K. Ungchittrakool, "Strong convergence theorems for a common fixed point of two relatively nonexpansive mappings in a Banach space," Journal of Approximation Theory, vol. 149, no. 2, pp. 103-115, 2007. 


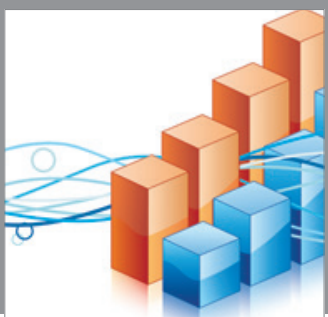

Advances in

Operations Research

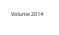

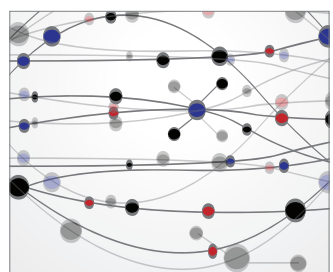

\section{The Scientific} World Journal
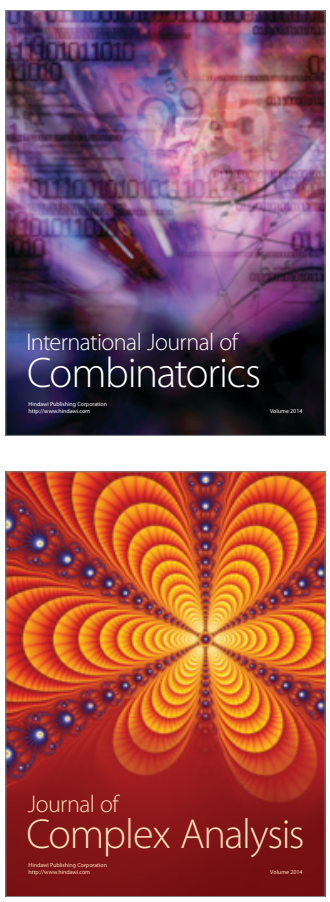

International Journal of

Mathematics and

Mathematical

Sciences
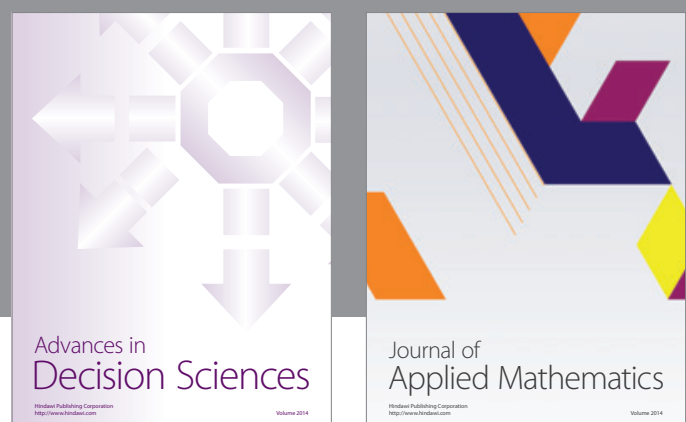

Journal of

Applied Mathematics
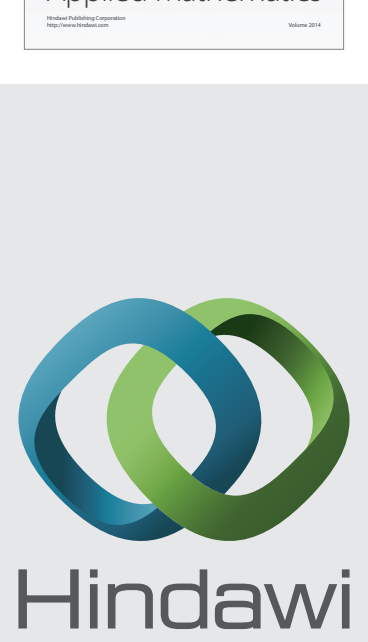

Submit your manuscripts at http://www.hindawi.com
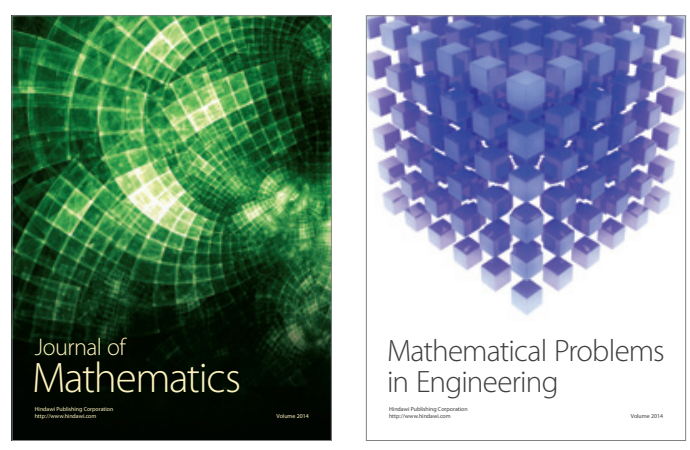

Mathematical Problems in Engineering
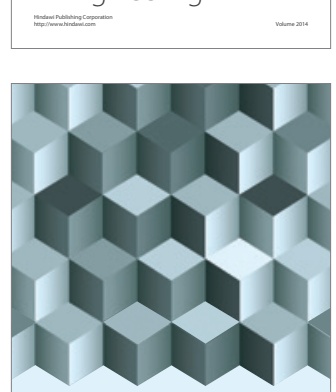

Journal of

Function Spaces
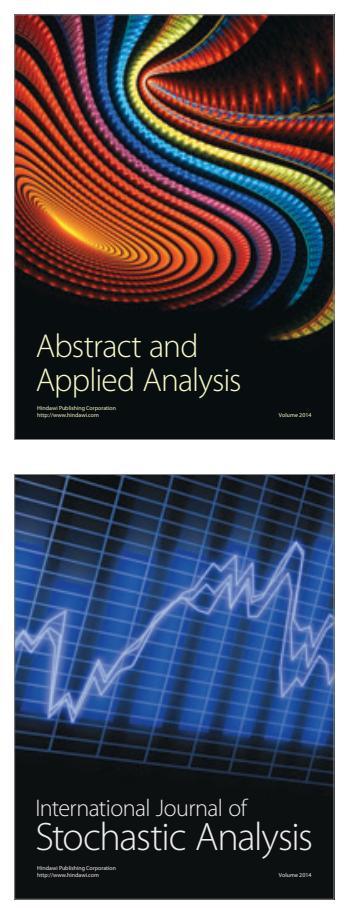

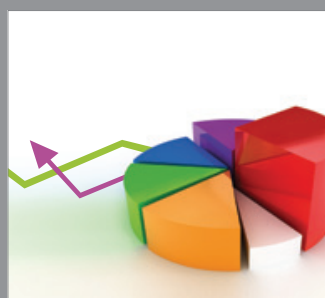

ournal of

Probability and Statistics

Promensencen
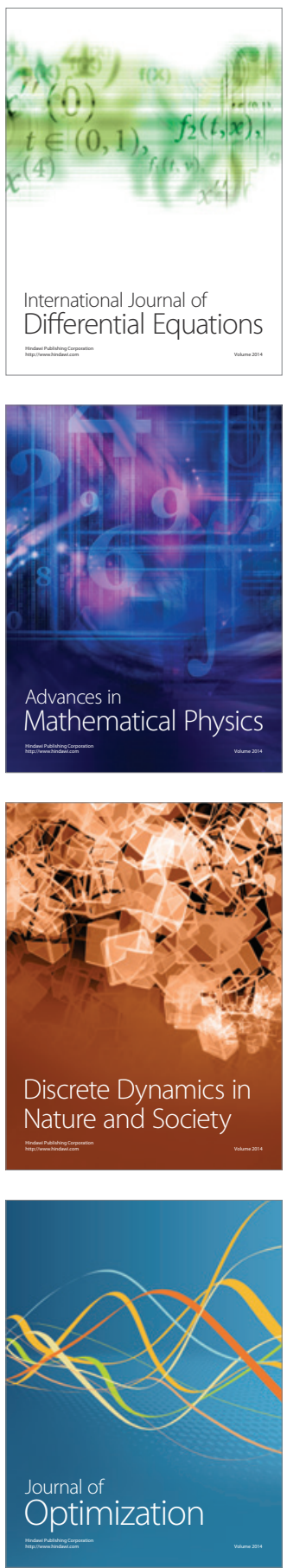